\title{
Does the Quality of Antenatal Care Predict Health Facility Delivery Among Women in Kenya? Further Analysis of KDHS Data 2008/09
}

\author{
Irene T. Obago ${ }^{1, *}$, James O. Ouma ${ }^{2}$ and Joyce A. Owino ${ }^{3}$ \\ ${ }^{1}$ Lecturer/Public Health Researcher, Center of Health Systems Research Excellence, Tropical Institute of \\ Community Health \& Development, Great Lakes University of Kisumu, P.O Box 2224-40100, Kisumu, Kenya \\ ${ }^{2}$ Lecturer Department of Nursing, Great Lakes University of Kisumu, P.O Box 2224-40100, Kisumu, Kenya \\ ${ }^{3}$ Dean of Faculty of Health Science, Lecturer Department of Nursing, Great Lakes University of Kisumu, P.O \\ Box 2224-40100, Kisumu, Kenya
}

\begin{abstract}
Improving maternal health remains a priority in Kenya and beyond. It is essential that women get good medical care before, during and after pregnancy to reduce maternal mortality. Skilled delivery care remains low in Kenya and maternal mortality rate high regardless of numerous ongoing interventions. Antenatal care is known to promote maternal and fetal well-being. However less than $50 \%$ of women make the recommended four or more antenatal care visits, missing out on key services such as urine and blood tests, and advice on possible pregnancy complications, that determine the quality of ANC. This study examines how the number of ANC visits and the quality of those visits predict health facility use at delivery.

Maternal health data from DHS of 2008/2008 in Kenya was analyzed using Stata 11.0 software. Logistic regression was used to evaluate relationships between facility delivery and predictor variables in univariate and multivariate models. Estimates were based on $95 \%$ confidence inteval. The models were examined at $95 \% \mathrm{Cl}$ and $80 \%$ power and adjusted for maternal age at last birth, education, place and type of residence, level of exposure to media, mother's religion, wealth index and birth order.

The quality of ANC was an index developed based on the number of services received during ANC visits. The quality of ANC visits progressively increased the likelyhood of health facility delivery. Supply and demand should be intervention targets to ensure that women know and understand the services to demand. Health facilities should also be sufficiently prepared and ready with the services.
\end{abstract}

Keywords: Kenya, antenatal care quality, health facility delivery.

\section{INTRODUCTION AND LITERATURE REVIEW}

Antenatal care is the medical care a woman receives during pregnancy. This care provides a key entry point for a range of preventive and promotive health services which help to ensure healthy outcomes for the mother and the newborn. For antenatal care to be effective it has to be of high quality where all essential services are provided. Antenatal care is central to the continuum of medical care that is necessary before and during pregnancy as well as at childbirth and postpartum. It is important in reducing maternal mortality, low birth weight and perinatal morbidity and mortality [1]. It is also an opportunity for mothers to access skilled care at delivery, usually at a health facility. Despite an overall increase in the number of women receiving antenatal care [2] few women make use of health facilities during delivery. As a result high maternal mortality rates continue to be registered each year, many of which result from complications related to pregnancy and child birth [3].

*Address correspondence to this author at the Lecturer/Public Health Researcher, Center of Health Systems Research Excellence, Tropical Institute of Community Health \& Development, Great Lakes University of Kisumu, P.O Box 2224-40100, Kisumu, Kenya; Tel: +254 721395 480;

E-mail: ireneobago@yahoo.com
Further, it has been shown that many more women are prone to injuries associated with pregnancy and delivery, which may result in significant risk $[7,8]$. High quality ANC has been shown to promote maternal and fetal well-being [1, 4-6].

An estimated 356,000 pregnancy related maternal deaths occurred in 2008 [9]. This was a $34 \%$ decline from the 1990 levels of 546,000 deaths. However, developing countries accounted for $99 \%$ of these deaths, with $87 \%$ being in Sub Saharan Africa and South Asia. In Sub Saharan Africa every woman faces a 1 in 31 adult lifetime risk of maternal death compared with only 1 in 4300 in developed regions [10]. In order to encourage interventions aimed at reducing maternal mortality, Millennium Development Goal 5 was focused on improving maternal health [12]. The aim was to reduce maternal mortality by $75 \%$ by 2015 . Between 1990 and 2008 there was only an average of $2.3 \%$ annual decline in maternal mortality globally, way below the projected target of $5.5 \%$ annual decline by 2015. The decline in Sub Saharan Africa was $0.1 \%$ and needs to increase precipitously in order to realize the target [11]. Indeed many SSA countries have made little progress [9, 12]. The proportion of women delivering under skilled care is used as a progress 
indicator for reducing maternal mortality as direct measurement of maternal mortality is difficult $[2,13]$.

Most maternal deaths occur during labor, delivery and the immediate postpartum period [10] due to preventable obstetric complications [14-16]. Access to a skilled birth attendant along with equipment, drugs and other medical supplies is currently promoted for preventing maternal deaths [10]. However, only $46 \%$ of patients receive such care in Africa [9]. In Kenya 43\% of women delivered at a health facility with skilled care [17]. This is far below the WHO recommendation of $60 \%$ [6]. Skilled care improves delivery outcome [18, 10]; and is used as a measure for assessing progress towards MDG 5 [9, 7]. Skilled delivery rates have improved over time [19, 9] but in Sub Saharan Africa the proportion of women receiving professional care at delivery has remained very low or increased very slightly [20]. Use of health facilities for delivery varies by socioeconomic status and place of residence [9]. Institutional births is negatively correlated with maternal age and birth order and this is more evident in Sub Saharan Africa, giving an indication than the use of health facilities for delivery in this region is a recent trend. Women living in urban areas are more likely to deliver in health facilities compared to those living in rural areas. The rate is also related with maternal education and wealth, as well as distance to health facilities.

In Kenya assisted delivery, along with institutional deliveries has ranged between $40 \%$ and $45 \%$ since the 1990s [4, 17, 18]. But this is not uniform nationwide; Mwaniki et al. (2002) and Eijk (2006) found rates between $12 \%$ to $20 \%$ in some districts [21, 22]. Numerous interventions including waiver of antenatal care fees, safe motherhood campaigns have turned out little gains [4]. The situation is complicated by the lay traditional birth attendants (TBA) previously promoted and placed in rural areas by the government and other partners [23]. The national average of deliveries by TBAs in 2008 was $28 \%$ but in many regions of the country, TBAs attend to over $70 \%$ of deliveries $[18,23]$. TBAs are more popular in rural communities [24] and may be linked to the low skilled care rate.

Skilled delivery attendance is modeled as a sequelae to antenatal care attendance [4, 5, 10, 25]. It creates an opportunity to deliver interventions for improving maternal nutrition, providing health education especially with the understanding of the need for women to prepare mentally, physically and logistically for childbirth [10] and risks of unattended delivery thereby encouraging skilled attendance at birth [18].
One study on the levels and trends in antenatal care conducted in the early 2000s based on household data from 49 African and Asian countries showed that the use of antenatal care in the developing world had incresed by $20 \%$ between $1990-2000$ [8]. While the developing world has achieved great success in antenatal care coverage with over $80 \%$ of women in many of the countries having at least one antenatal care visit, many Sub Saharan African and Asian countries still have unsatisfactory levels of the WHOrecommended four or more antenatal care visits [18]. It is however encouraging that the data on trends in having at least four antenatal care visits show improvements since 1990 in most countries.

Most women in Sub Saharan Africa delay the initial ANC visit to the second or third trimester and fail to make the recommended minimum of four visits $[4,5$, 24]. In Kenya over $90 \%$ of women make at least one antenatal care visit but only less than $50 \%$ reach the minimum of four thus missing out on key linked services including urine and blood tests, and monitoring of possible complications [17]. This may interrupt the quality continuum of care.

Use of skilled health providers in providing antenatal care has been increasing in most developing countries since the 1990s [9]. While doctors are the main providers in latin america and the carribean, in Sub Saharan Africa women rely pimarily on nurses and/or midwives for such care. Rarely are traditional attendants and health care providers other than nurses, and midwives reported as providers of antenatal care. There appears to be a strong association between a woman receiving antenatal care from a skilled health care provider and residence in an urban area rather than a rural area, having a higher education level and coming from a richer household [4, 9, 18]. The socioeconomic gap in antenatal care is considerably larger in countries where overall use of skilled health providers is low.

While the number of women with access to atleast one antenatal care visit is easily and regularly monitored and has improved in many countries, much has not been done in monitoring and measuring the content and quality of this care [1,26]. Full access to antenatal care may not suffice, as many women who attend ANC do not always deliver at a health facility $[26,27]$. It is necessary to evaluate if quality of ANC could predict skilled delivery care at a health facility [1, $26,28]$. The inquiry should include the salient quality attributes that may predict the care. The investigation 
into the quality may be set from myriad perspectives, including the structure, process and outcome. It can also be assessed by looking at the clinical quality or interpersonnal quality [1]. Tests and services by a skilled health care provider such as measurement of weight, height, blood pressure, urine and blood testing, abdomen examination, provision of iron and folic acid supplementation and tetanus toxoid examination all constitute measurement of clinical quality, in addition to provision of information on nutrition, information on nutrition, danger signs of pregnancy, delivery care, newborn care and family planning $[1,10,15]$.

So far most studies have focused on the number of antenatal care and health facility delivery. This study goes further to examine the quality of such ANC in terms of the services provided, and how that quality related with health facility delivery.

It has been reported that $\mathrm{ANC}$ alone could reduce maternal death rate by more than $20 \%$ provided it is of good quality and regularly attended by pregnant women [18]. However, there is scarce information about the quality of care provided during ANC in Kenya and in several other countries as well, and its role in predicting health facility delivery. This study examines the quality of care provided during antenatal care, and how this predicts use of health facilities for delivery. In this study, quality of antenatal care is based on clinical quality and only limited to measurement of blood pressure, urine and blood testing and provision of information on danger signs associated with pregnancy. An index based on these four services is developed and is used in the analysis.

The outcome variable of interest is health facility delivery. Different levels of grouping of the independent variables represent the proximity of the factors to the dependent variable being measured. Background modifying factors may influence the dependent variable indirectly while the proximate factors may have a direct effect. The background factors may also modify the association between proximate and outcome factors in some way. The main explanatory factors for use of health facilities for delivery are number of antenatal care visits and the quality of antenatal care. Possible associations between the dependent and independent variables are examined in this study.

\section{RESEARCH QUESTIONS}

Does antenatal care predict use of health facilities for delivery among pregnant women in Kenya?

1. Does number of ANC visits matter?

For this question associations between the number of ANC visits and delivery at a health facility are examined

\section{Does quality of ANC matter?}

For this question the relationship between quality of ANC visit and delivery at a health facility are examined
Background factors
(covariates)

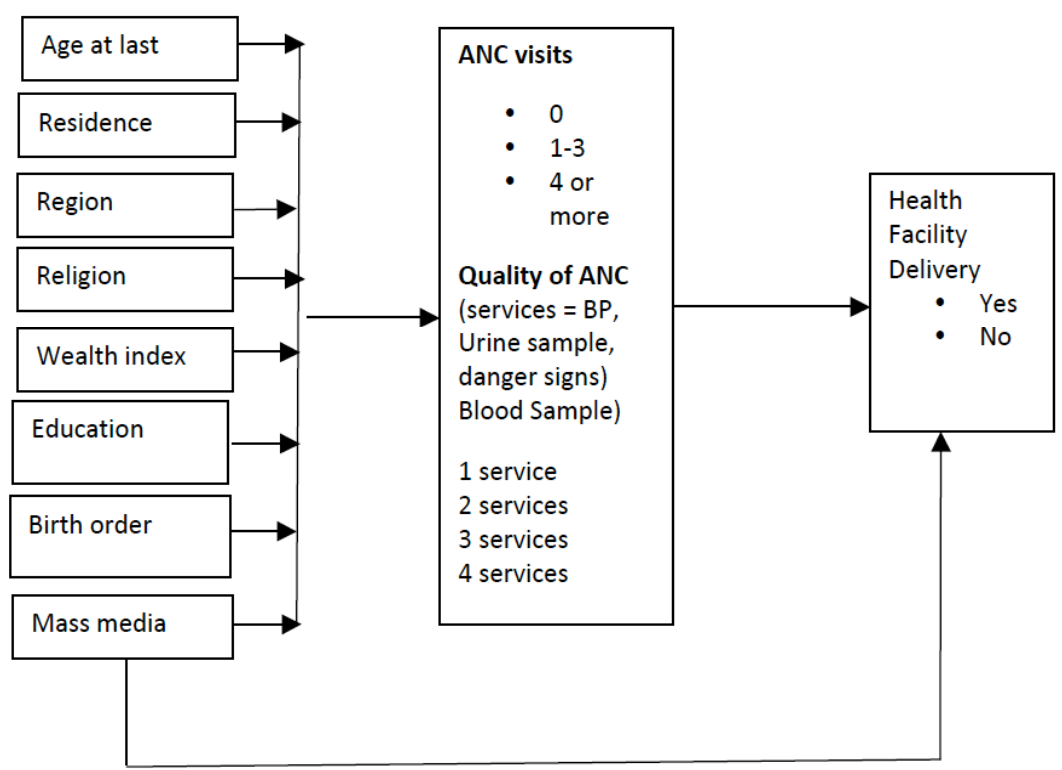

Outcome

(Response) 


\section{Defination of Key Variables}

These concepts in the conceptual framework which are also the study variables are descrbed as follows:

\begin{tabular}{|c|c|c|c|c|c|c|c|}
\hline & Variable & Measure & Description & & Variable & Measure & Description \\
\hline \multicolumn{4}{|c|}{ Responce } & & \multicolumn{3}{|l|}{ Responce } \\
\hline 1. & $\begin{array}{l}\text { Health } \\
\text { facility } \\
\text { delivery }\end{array}$ & $\begin{array}{l}0 \text { Other, HF } \\
\text { delivery }\end{array}$ & $\begin{array}{l}1 \text { Includes all } \\
\text { deliveries at an } \\
\text { institution. This is } \\
\text { the main outcome } \\
\text { variable of interest }\end{array}$ & 4. & $\begin{array}{l}\text { Mother's age } \\
\text { at last birth }\end{array}$ & $\begin{array}{l}115-24,224- \\
34,334+\end{array}$ & \\
\hline \multicolumn{4}{|c|}{ Independent covariates } & 5. & $\begin{array}{l}\text { Type pf } \\
\text { residence }\end{array}$ & $\begin{array}{l}\text { 0 Rural, } 1 \\
\text { Urban }\end{array}$ & \\
\hline 2. & $\begin{array}{l}\text { No. of } \\
\text { ANC visits }\end{array}$ & $\begin{array}{l}10 \text { visit, } 21-3 \\
\text { visits, } 34 \text { or } \\
\text { more visits }\end{array}$ & $\begin{array}{l}\text { Categorizes } \\
\text { number of ANC } \\
\text { visits into three } \\
\text { groups }\end{array}$ & 6. & Province & $\begin{array}{l}1 \text { Nairobi, } 2 \\
\text { Central, } 3 \\
\text { Coast, } 4 \\
\text { Eastern, } 5 \\
\text { Nyanza, 6 R. } \\
\text { Valley, } 7 \\
\text { Western, } 8 . \\
\text { North Eastern }\end{array}$ & \\
\hline \multirow[t]{10}{*}{3.} & \multirow[t]{10}{*}{$\begin{array}{l}\text { Quality of } \\
\text { ANC }\end{array}$} & 0 service & $\begin{array}{l}\text { An index is } \\
\text { developed for } \\
\text { quality of ANC } \\
\text { based on the four } \\
\text { services outlined } \\
\text { below that are } \\
\text { provided during the } \\
\text { visits. ANCQLO - } \\
\text { no service } \\
\text { provided }\end{array}$ & 7. & Religion & $\begin{array}{l}0 \text { No religion, } 1 \\
\text { Catholic, } 2 \\
\text { Protestant, } 3 \\
\text { Muslim }\end{array}$ & \\
\hline & & ANCQL1 & $\begin{array}{l}1 \text { service }-1 \text { of } 4 \\
\text { service provided } \\
\text { (Ref) }\end{array}$ & 8. & $\begin{array}{l}\text { Education } \\
\text { level }\end{array}$ & $\begin{array}{l}1 \text { No education, } \\
2 \text { Primary, } 3 \\
\text { Secondary }+\end{array}$ & \\
\hline & & ANCQL2 & $\begin{array}{l}-2 \text { services }-2 \text { of } \\
4 \text { services } \\
\text { provided }\end{array}$ & 9. & Birth order & $\begin{array}{l}11-3,24-5,3 \\
6+\end{array}$ & \\
\hline & & ANCQL3 & $\begin{array}{l}\text { - } 3 \text { services }-3 \text { of } \\
4 \text { services } \\
\text { provided }\end{array}$ & $\begin{array}{l}10 \\
\cdot\end{array}$ & Wealth index & $\begin{array}{l}1 \text { Poorest, } 2 \\
\text { Poorer, } 3 \\
\text { Middle, } 4 \\
\text { Richer, } 5 \\
\text { Richest }\end{array}$ & \\
\hline & & ANCQL4 & $\begin{array}{l}\text { - } 4 \text { services }-4 \text { of } 4 \\
\text { services provided }\end{array}$ & $\begin{array}{l}11 \\
\cdot\end{array}$ & Mass media & MMedia 0 & $\begin{array}{l}\text { An index developed for level of } \\
\text { exposure to mass media (Listening to } \\
\text { radio, watching television and } \\
\text { reading newspapers) }\end{array}$ \\
\hline & & & & & & MMedia 1 & $\begin{array}{l}\text { MMedia } 0 \text { - exposure to any three } \\
\text { less than once a week }\end{array}$ \\
\hline & & & & & & MMedia 2 & $\begin{array}{l}\text { MMedia } 1 \text { - exposure to any one at } \\
\text { least once a week }\end{array}$ \\
\hline & & & & & & MMedia 3 & $\begin{array}{l}\text { MMedia } 2 \text { - exposure to any two at } \\
\text { least once a week }\end{array}$ \\
\hline & & & & & & & $\begin{array}{l}\text { MMedia } 3 \text { - exposure to any three at } \\
\text { least once a week }\end{array}$ \\
\hline & & & & & & & \\
\hline
\end{tabular}

\section{METHODS}

Data from the demographic health survey conducted in Kenya during 2008/2009 was analyzed for this research paper. Kenya Demographic Health Survey (KDHS) is conducted in Kenya every five years since the 80's and the data is available to the public. The most recent survey was conducted at the end of 2008 and the start of 2009. The design used for the surveys is cross-sectional and employs a systematic two-stage cluster sampling technique to select the households to be included in the sample. The sample is always nationally representative. In the last DHS, a total of 8, 444 women aged 15-49 were interviewed. The population of interest in this study are women aged 15-49 who had a birth in the last five years preceding the survey. Data on births that occured during the five years preceding the survey was used, and the analysis 
is restricted to the last birth to 3973 women. Information on most recent birth was used as it is for this birth that antenatal care information was available. Because this research was based on secondary analysis of publicly available data, no ethical considerations were needed before the undertaking.

\section{Sample Design}

The sampling strategy in the 2008/09 survey as with all other surveys was a two-stage cluster sample: a selection of clusters from a national master sample and sampling of households from a list of all households from the sampled clusters. The sample drawn allowed for separate estimates of key indicators for each of the country's 8 provinces and for urban and rural separately [17].

\section{Analysis Methods}

Data was analyzed using Stata 11.0 statistical software. All numbers are weighted to accommodate non- response, over and under sampling. The sample was described using frequencies in percentages. Both univariable and multivariable logistic regression analyses were employed. Results are reported based on $95 \%$ confidence intervals. Three models are reported: Model 1 describes the unadjusted odds ratios, Model 2 adjusts for number of ANC visits and quality of ANC as applicable for both objectives, Model

Table 1: Sample Characteristics of Women Aged 15-49 Years who had a Live Birth During the Five Years Preceding the 2008/2009 KDHS, Restricted to the Most Recent Birth

\begin{tabular}{|c|c|c|c|c|c|}
\hline RESPONSE & n(weighted) & $\%$ & Other characteristics & n(weighted) & $\%$ \\
\hline HF delivery & & & Level of exposure to media & & \\
\hline No & 2115 & 53.24 & MMedia 0 & 850 & 21.38 \\
\hline Yes & 1858 & 46.76 & MMedia 1 & 1902 & 47.88 \\
\hline MAIN COVARIATES & & & MMedia 2 & 782 & 19.68 \\
\hline Number of ANC visits & & & MMedia 3 & 439 & 11.06 \\
\hline 0 & 290 & 7.29 & Residence type & & \\
\hline $1-3$ & 1730 & 43.54 & Urban & 823 & 20.71 \\
\hline $4+$ & 1953 & 49.17 & Rural & 3150 & 79.29 \\
\hline Quality of ANC & & & Religion & & \\
\hline ANCQL 0 & 542 & 13.64 & No religion & 137 & 3.45 \\
\hline ANCQL 1 & 373 & 9.38 & Catholic & 820 & 20.64 \\
\hline ANCQL 2 & 543 & 13.67 & Protestant & 2698 & 67.9 \\
\hline ANCQL 3 & 1297 & 32.65 & Muslim & 318 & 8.01 \\
\hline ANCQL 4 & 1218 & 30.67 & Province & & \\
\hline OTHER COVARIATES & & & Nairobi & 269 & 6.76 \\
\hline Mother's characteristics & & & Central & 371 & 9.33 \\
\hline Age at last birth & & & Coast & 330 & 8.3 \\
\hline $15-24$ & 1795 & 45.17 & Eastern & 630 & 15.85 \\
\hline $25-34$ & 1652 & 41.59 & Nyanza & 733 & 18.44 \\
\hline $35+$ & 526 & 13.24 & Rift valley & 1103 & 27.77 \\
\hline Maternal education & & & Western & 442 & 11.12 \\
\hline No education & 441 & 11.01 & North Eastern & 97 & 2.43 \\
\hline Primary & 2487 & 62.58 & Wealth index & & \\
\hline Secondary and above & 1045 & 26.31 & Poorest & 843 & 21.21 \\
\hline Birth order & & & Poorer & 764 & 19.22 \\
\hline $1-3$ & 2378 & 59.85 & Middle & 742 & 18.67 \\
\hline $4-5$ & 829 & 20.87 & Richer & 765 & 19.26 \\
\hline $6+$ & 766 & 19.28 & Richest & 859 & 21.63 \\
\hline
\end{tabular}


3 adjusts for mother's age at birth, education, exposure to media, wealth index, birth order, religion, region and residencs in addition to those adjusted for in model 2.

\section{RESULTS}

\section{Sample Description}

Table 1 shows the characteristics of the 3973 women aged 15-49 at the birth of their most recent child. The majority were aged 34 and below. Slightly more than $50 \%$ had their child in a health facility. As expected only $7 \%$ had no antenatal care visit and about 50 percent made four or more ANC visits. About 30\% received all four services during ANC. The sample was nearly equally distributed within the five wealth quintiles, and about $70 \%$ resided in rural areas.

\section{Characteristics of Women Delivering in a Health Facility}

Table 2 describes the characteristics of women who delivered in a health facility. As expected only $11 \%$ of

Table 2: Percent Distribution of Women Aged 15-49 who had a Live Birth in the 5 Years Preceding the Survey by Health Facility Delivery for the Most Recent Birth, According to Background Characteristics, Kenya 2008/09

\begin{tabular}{|c|c|c|c|c|c|}
\hline MAIN COVARIATES & HF delivery \% * & Total $^{\star \star}$ & Residence type & HF delivery \% * & Total $^{\star \star}$ \\
\hline Number of ANC visits & & & Urban & 823 & 75.76 \\
\hline 0 & 290 & 10.72 & Rural & 3150 & 39.18 \\
\hline $1-3$ & 1730 & 38.21 & Religion & & \\
\hline $4+$ & 1953 & 59.66 & No religion & 137 & 22.63 \\
\hline Quality of ANC & & & Catholic & 820 & 48.54 \\
\hline ANCQL 0 & 542 & 13.69 & Protestant & 2698 & 48.3 \\
\hline ANCQL 1 & 373 & 19.27 & Muslim & 318 & 39.46 \\
\hline ANCQL 2 & 543 & 34.86 & Province & & \\
\hline ANCQL 3 & 1297 & 53.56 & Nairobi & 269 & 90.28 \\
\hline ANCQL 4 & 1218 & 67.92 & Central & 271 & 74.34 \\
\hline OTHER COVARIATES & & & Coast & 330 & 49.2 \\
\hline Mother's characteristics & & & Eastern & 630 & 49.63 \\
\hline Age at last birth & & & Nyanza & 733 & 47.29 \\
\hline $15-24$ & 1795 & 49.28 & Rift valley & 1103 & 33.71 \\
\hline $25-34$ & 1652 & 47.09 & Western & 442 & 29.11 \\
\hline $35+$ & 526 & 37.09 & North Eastern & 97 & 18.45 \\
\hline Maternal education & & & Wealth index & & \\
\hline No education & 441 & 17.17 & Poorest & 843 & 18.84 \\
\hline Primary & 2487 & 40.74 & Poorer & 764 & 32.25 \\
\hline Secondary and above & 1045 & 73.55 & Middle & 742 & 45.22 \\
\hline Birth order & & & Richer & 765 & 55.08 \\
\hline $1-3$ & 2378 & 56.68 & Richest & 859 & 80.92 \\
\hline $4-5$ & 829 & 37.08 & Total & & 3973 \\
\hline $6+$ & 766 & 26.43 & & & \\
\hline \multicolumn{6}{|l|}{$\begin{array}{l}\text { Level of exposure to mass } \\
\text { media }\end{array}$} \\
\hline MMedia 0 & 850 & 26.73 & & & \\
\hline MMedia 1 & 1902 & 39.29 & & & \\
\hline MMedia 2 & 782 & 65.56 & & & \\
\hline MMedia 3 & 439 & 84.32 & & & \\
\hline
\end{tabular}

*Includes percent deliveries at a government hospital, health center, other public hospital, mission hospital/clinic, private hospital/clinic, nursing maternity home or other private medical facility. ${ }^{*}$ Weighted numbers. 
those with no ANC delivered in a facility compared to $60 \%$ of those who had at least four visits. Only $37 \%$ of those aged 35 and above delivered in a facility. Of those who received all four services during ANC, over $65 \%$ had their children in a health facility as did $90 \%$ of those who reside in Nairobi.

\section{Association between Health Facility Delivery and Dependent Variables}

Table 3 shows the unadjusted odds ratios for a number of covariates. Women with four ANC visits or more were 12 times more likely to deliver at a faclity $(95 \% \mathrm{Cl} 6.6-23.10)$, compared to those with none. Similarly, use of facilities for deliveries increased with an increase in the quality of care. Those who received four services were about 9 times more likely to deliver at a facility compared to their counterparts with only counteroarts with only one service $(95 \% \mathrm{Cl} 6.3-12.5)$.

\section{Examining Weather Quality and Number of ANC Visits Influence Health Facility Delivery}

Table 4 shows adjusted associations between health facility delivery versus number of ANC visits and quality of ANC. As indicated, Model 2 in the second panel adjusts for number of ANC visits and quality of ANC. In addition to these, model 3 adjusts for other important covariates such as age at birth, education level, birth order, level of exposure to media, type of residence, place of residence, religion, province and wealth index. The percentage of women delivering at a health facility has a significant association with four or more ANC visits (AOR 2.5, 1.1-5.9) in the multivariable analysis after controlling for quality of care and the other potential confounders. Similarly, the quality of ANC significantly predicts health facility delivery. Women who received two (AOR 2.3, 95\% Cl 1.613.18), three (AOR $3.295 \% \mathrm{Cl} 2.16-4.79$ ) or four (AOR

Table 3: Unadjusted Odds Ratio (UOR) of Various Covariates on Health Facility Delivery (No hf Delivery vs Health Facility Delivery) for Women Age 15-49 who had a Live Birth in the 5 Years Preceding the Survey, for the Most Recent Birth, Kenya 2008/09

\begin{tabular}{|c|c|c|c|}
\hline \multicolumn{4}{|l|}{ Proximate covariates } \\
\hline Number of ANC visits (ref $=0$ ) & UOR $^{\star}(95 \% \mathrm{Cl})$ & Residence type (ref rural) & UOR $^{\star}(95 \% \mathrm{Cl})$ \\
\hline $1-3$ & $5.15(2.75-9.63)^{\star *}$ & Urban & $4.85(3.34-7.05)^{* *}$ \\
\hline $4+$ & $12.31(6.56-23.10)^{* *}$ & Religion (ref no religion) & \\
\hline Quality of ANC (ref = 1) & & Catholic & $3.23(1.59-6.55)^{* *}$ \\
\hline ANCQL 0 & $0.7(0.42-1.04)$ & Protestant & $3.19(1.56-6.53)^{\star *}$ \\
\hline ANCQL 2 & $2.2(1.61-3.11)^{* *}$ & Muslim & $2.23(0.99-5.03)$ \\
\hline ANCQL 3 & $4.8(3.40-6.86)^{\star *}$ & Province (ref Nairobi) & \\
\hline ANCQL 4 & $8.9(6.32-12.45)^{\star *}$ & Central & $0.31(0.15-0.65)^{\star *}$ \\
\hline Other covariates & & Coast & $0.10(0.05-0.21)^{* *}$ \\
\hline Mother's characteristics & & Eastern & $0.11(0.05-0.22)^{\star *}$ \\
\hline Age at last birth $($ ref $=15-24)$ & & Nyanza & $0.10(0.05-0.19)^{\star *}$ \\
\hline $25-34$ & $0.92(0.74-1.14)$ & Rift valley & $0.06(0.03-0.11)^{* *}$ \\
\hline $35+$ & $0.61(0.47-0.79)^{\star *}$ & Western & $0.04(0.02-0.06)^{* *}$ \\
\hline Maternal education (ref No education) & & North Eastern & $0.02(0.01-0.06)^{\star *}$ \\
\hline Primary & $3.32(2.11-5.21)^{\star *}$ & Wealth index (ref poorest) & \\
\hline Secondary and above & $13.42(8.04-22.40)^{* *}$ & Poorer & $2.05(1.45-2.91)^{\star *}$ \\
\hline Birth order $(6+)$ & & Middle & $3.56(2.58-4.91)^{\star *}$ \\
\hline $4-5$ & $1.6(1.2-2.26)^{\star *}$ & Richer & $5.28(6.60-7.74)^{* *}$ \\
\hline $1-3$ & $3.6(2.77-4.79)^{\star *}$ & Richest & $18.26(11.48-29.06)^{* *}$ \\
\hline \multicolumn{4}{|l|}{ Level of exposure to media (ref $=0$ ) } \\
\hline MMedia 1 & $1.77(1.30-2.43)^{\star *}$ & & \\
\hline Mmeda 2 & $5.22(3.74-7.27)^{\star *}$ & & \\
\hline MMedia 3 & $14.74(9.43-23.02)^{\star *}$ & & \\
\hline
\end{tabular}


Table 4: Adjusted Odds Ratio of Various Covariates on Health Facility Delivery (No hf Delivery vs Health Facility Delivery) for Women Age 15-49 who had a Live Birth in the 5 Years Preceding the Survey, for the Most Recent Birth, Kenya 2008/09

\begin{tabular}{|c|c|c|c|c|}
\hline $\begin{array}{l}\text { Proximate } \\
\text { covariates }\end{array}$ & MODEL 2: AOR (95\%Cl) & $\begin{array}{l}\text { MODEL 3: } \\
\text { AOR }(95 \% \mathrm{Cl})\end{array}$ & & $\begin{array}{l}\text { MODEL } 3(\ldots \text { cont }): \\
\text { AOR }(95 \% \mathrm{Cl})\end{array}$ \\
\hline $\begin{array}{l}\text { Number of ANC } \\
\text { visits }(\text { ref }=0)\end{array}$ & & & $\begin{array}{l}\text { Residence type } \\
\text { (ref rural) }\end{array}$ & \\
\hline $1-4$ & $1.4(0.59-3.11)$ & $1.7(0.77-3.86)$ & Urban & $0.89(0.52-1.51)$ \\
\hline $4+$ & $2.5\left(1.06-6.04^{*}\right)$ & $2.53(1.1-5.86)^{*}$ & $\begin{array}{l}\text { Religion (ref } \\
\text { protestant) }\end{array}$ & \\
\hline $\begin{array}{l}\text { Quality of ANC (ref = } \\
\text { 1) }\end{array}$ & & & Catholic & $0.6(0.24-1.41)$ \\
\hline ANCQL 0 & $0.9(0.51-1.50)$ & $0.8(0.45-1.47)$ & Protestant & $0.9(0.73-1.16)$ \\
\hline ANCQL 2 & $2.2(1.59-3.06)$ * & $2.3(1.61-3.18)^{*}$ & Muslim & $1.2(0.64-2.24)$ \\
\hline ANCQL 3 & $4.4(3.07-6.31) *$ & $3.2(2.16-4.79)^{*}$ & $\begin{array}{l}\text { Province (ref } \\
\text { Nairobi) }\end{array}$ & \\
\hline ANCQL 4 & $7.6(5.46-10.72) *$ & $4.1(2.8-6.0)^{*}$ & Central & $0.9(0.4-2.1)$ \\
\hline Other covariates & & & Coast & $0.43(0.20-0.90)^{*}$ \\
\hline $\begin{array}{l}\text { Mother's } \\
\text { characteristics }\end{array}$ & & & Eastern & $0.6(0.24-1.3)$ \\
\hline $\begin{array}{l}\text { Age at last birth }(\text { ref }= \\
15-24)\end{array}$ & & & Nyanza & $0.5(0.22-1.09)$ \\
\hline $25-34$ & & $1.0(0.72-1.41)$ & Rift valley & $0.23(0.1-0.55)^{*}$ \\
\hline $35+$ & & $1.0(0.61-1.74)$ & Western & $0.19(0.09-0.44)^{*}$ \\
\hline $\begin{array}{l}\text { Marernal education } \\
\text { (ref = No education) }\end{array}$ & & & North Eastern & $0.4(0.15-1.05)$ \\
\hline Primary & & $1.69(1.03-2.79)^{*}$ & $\begin{array}{l}\text { Wealth index (ref } \\
\text { poorest) }\end{array}$ & \\
\hline Secondary and above & & $3.35(1.83-6.14)^{*}$ & Poorer & $1.4(0.95-2.03)$ \\
\hline Birth order $($ ref $=1-3$ ) & & & Middle & $1.88(1.31-3.70)^{\star}$ \\
\hline $4-5$ & & $0.6(0.45-0.79)^{*}$ & Richer & $2.0(1.31-3.04)^{*}$ \\
\hline $6+$ & & $0.7(0.42-1.05)$ & Richest & $4.38(2.6-7.38)^{*}$ \\
\hline \multicolumn{5}{|l|}{$\begin{array}{l}\text { Level of exposure to } \\
\text { media }(\text { ref }=0)\end{array}$} \\
\hline \multicolumn{5}{|l|}{ MMedia 1} \\
\hline MMeda 2 & & $1.63(1.13-2.34)^{*}$ & & \\
\hline MMedia 3 & & $2.43(1.42-4.15)^{*}$ & & \\
\hline
\end{tabular}

$4.195 \% \mathrm{Cl}$ 2.8-6.0) services during ANC were significantly more likely than their counterparts with only one service, to deliver at a health facility. Other covariates found to be significantly associated with health facility delivery were higher education level, lower birth order, higher level of exposure to media and place of residence. Women who resided in Coast, rift valley and western provinces were less likely to deliver at a health facility compared to those in Nairobi. Also the likelihood of delivering at a facility increased with an increase in wealth.

\section{DISCUSSION}

In the introduction, the need for quality antenatal care was highlighted as a way to improve maternal well being $[1,4,5,10]$ and in turn lead to reduction in maternal mortality [1]. It provides a crucial link in the continuum of care necessary during pregnancy, childbirth and postpartum. It was also noted that pregnant women should have the recommended four or more antenatal care visits so they do not miss out on the key services such as monitoring of blood pressure, counselling on complications that might arise during 
pregnancy $[10,29]$, and that ANC provides an opportunity for women to be encouraged to make use of skilled care at health facilities during delivery [18]. In Kenya, while nearly all women who had a birth in the five years preceding the 2008/2009 demographic health survey had at least one ANC visit, less than fifty percent had the recommended four. In addition, not all women receive the recommended services during these visits. Furthemore, findings from this study show that only $47 \%$ had their last birth under skilled care at a health facility. This study examined the role antenatal care plays in predicting health facility use for delivery. Specifically, number of ANC visits and quality of these visits in influencing health facility delivery among women in Kenya was assessed.

In interpreting the findings a few limitations should be considered: since the DHS is crossestional, causality cannot be established. Also while there is a wide range of services provided during ANC, this study was limited to only four clinical services and by no means captures the wide range of care. The rate of skilled delivery has been shown to be less than $50 \%$ in Kenya and indicates that the country still has to step up interventions for reducing maternal mortality. The results demonstrate the association between number of antenatal care and quality of this care and health facility delivery. Consistent with studies by others [4, $15,18]$, findings from this study show that number of ANC visits mattered in predicting health facility use for delivery. Women with more antenatal care visits were more likely to deliver at a health faciltity. The effect of antenatal care illustrates the roles that care during pregnancy has in informing women of the importance of delivering at a health facility. It follows therefore that women who utilize pregnacy care are also more likely to seek skilled care for delivery [29]. It is likely that these women have similar characteristics that cause them to have similar health seeking behaviour, such as higher education and higher exposure to media.

Quality of antenatal care has been recognized as a determinant in the use of health services [5]. This study has demonstrated a positive and significant association between women who receive more services during antenatal care and delivering under skilled attendance at a health facilty. It follows that not only ANC visits but the care provided during the visits completes the continuum of care necessary to ensure maternal health and hence reduce maternal mortality.

The main conclusions from this study are that the number of antenatal care visits together with the quality of these visits play a significant role in predicting health facility use for delivery, among women in Kenya. Women with more ANC visits as well as those receiving more services are more likely to deliver at a health facility than those with fewer visits and those receiving less services respectively. Other important covariates for facility delivery that were identified include level of education, exposure to media, and wealth. Interventions therefore, should not only be targeted at encouraging more number of ANC visits, but at ensuring that the required number of services is provided during these visits as well. Women should be educated on what services to expect when they attend ANC, so that they are able to demand these services.

\section{ACKNOWLEDGEMENT}

ICF International fellowship for junior faculty 2012.

\section{REFERENCES}

[1] Rani M, Bonu S, Harvey S. Differentials in the quality of antenatal care in India. Int J Qual Health Care 2007; 20(1): 62-71. http://dx.doi.org/10.1093/intghc/mzm052

[2] De Bernis L, Sherratt D, AbouZahr C, Van Lerberghe W. Skilled attendants for pregnancy, childbirth and postnatal care. Br Med Bull 2003; 67: 39-57.

http://dx.doi.org/10.1093/bmb/ldg017

[3] Ronsmans C, Graham WJ. Maternal mortality: who, when, where, and why. Lancet 2006; 368(9452): 1189-200. http://dx.doi.org/10.1016/S0140-6736(06)69380-X

[4] Ochako R, Fotso J, Ikamari L, Khasakhala A. Utilization of maternal health services among young women in Kenya: Insights from Kenya Demographic Health Survey, 2003. BMC Pregnancy and Childbirth 2011; 11: 1.

[5] Chen XK, Wen SW, Yang Q, Walker MC. Adequacy of prenatal care and neonatal mortality in infants born to mothers with and without antenatal high-risk conditions. Aust NZ J Obetet Gynaecol 2007; 47(2): 122-7.

[6] WHO/UNICEF. (2003). Antenatal Care in Developing Countries: promises, achievements and missed opportunities: an analysis of trends, levels and differentials, 1990-2001; 2003.

[7] Fotso JC, Ezeh A, Oronje R. Provision and use of maternal health services among urban poor women in Kenya: what do we know and what can we do. J Urban health 2008; 85: 3. http://dx.doi.org/10.1007/s11524-008-9263-1

[8] AbouZahr C, Wardlaw T. Maternal mortality at the end of the decade: signs of progress? Bull World Health Organ 2001; 79: 561-68.

[9] Wang W, Alva S, Wang S, Fort A. Levels and trends in the use of maternal health services in developing countries. Calverton, Maryland USA: ICF Macro 2011.

[10] WHO, ICM, and FIGO. Making pregnancy safer: the critical role of the skilled attendant. A joint statement by WHO, ICM and FIGO. Geneva: World Health Organization 2004.

[11] Department for International Development: DFID'S Maternal Health Strategy Reducing maternal deaths: evidence and action. DFID Second Progress Report 2007.

[12] United Nations. General Assembly. Resolution adopted by the General Assembly. United Nations Millennium Declaration, 55th session, $18^{\text {th }}$ September, 2000. New York, 
NY: United Nations, 2000. 9 p. (http://www.un.org/ millennium/declaration/ares552e.pdf, Accessed on 11 December, 2011).

[13] Campbell $O$. Measuring progress in safe motherhood programs: uses and limitations of health outcome indicators. In: Berer M, Ravindran TKS, editors. Safe motherhood initiatives: critical issues. Oxford: Blackwell Science 1999; pp. 31-42.

[14] Ministry of Health [Kenya], National Council for Population and Development [Kenya], and ORC Macro. Kenya Service Provision Assessment Survey 1999. Calverton, Maryland: Ministry of Health, National Council for Population and Development, and ORC Macro 2000.

[15] Chou D, Inoue M, Mathers C, Oestergaard M, Say L, Mills S. et al. Trends in Maternal mortality estimates 1990-2008. WHO, UNICEF, UNFPA and the World Bank Geneva 2010.

[16] Pembe A, Varlstedt A, Urassa D, Lindmark G, Nystrom L, Darj E. Quality of antenatal care in Rural Tanzania: counseling on pregnancy danger signs. BMC Pregnancy Childbirth 2010; 10(35).

[17] Central Bureau of Statistics (CBS) [Kenya], Ministry of Health $(\mathrm{MOH})$ [Kenya], ORC Macro: Kenya Demographic and Health Survey 2008/2009. CBS, MOH, ORC Macro 2009

[18] Wanjira C, Mwangi M, Mathenge E, Mbugua G, Ng'ang'a Z. Delivery Practices and Associated Factors among Mothers Seeking Child Welfare Services in Selected Health Facilities in Nyandarua South District, Kenya. BMC Public Health $2011 ; 11: 360$. http://dx.doi.org/10.1186/1471-2458-11-360

[19] Bell J, Curtis S, Alayón S. Trends in delivery care in six countries. In DHS analytical studies N0.7. Calverton, Maryland USA: ICF Macro and International Research Partnership for Skilled Attendance for Everyone (SAFE) 2003.

[20] United Nations 2006. The Millennium Development Goals Report 2006. New York 2006.
[21] Mwaniki P, Kabiru E, Mbugua G. Utilization of antenatal and maternity services by mothers seeking child welfare services in Mbeere District, Eastern Province, Kenya. East Afr Med J 2002; 79: 184-87.

http://dx.doi.org/10.4314/eamj.v79i4.8875

[22] Eijk A, Bles H, Odhiambo F, Ayisi J, Blokland I, Rosen D, et al. Use of antenatal services and delivery care among women in rural Western Kenya: a community based survey. J Reprod Health 2006; 3(2): 1-9.

[23] MOH/UNFPA: Needs assessment of obstetric fistula in Kenya. Final report by division of reproductive health; 2004 [http://www.endfistula.org/docs/ na_kenya.pdf].

[24] Izugbara C, Ezeh A, Fotso JC. The persistence and challenges of homebirths: perspectives of traditional birth attendants in urban Kenya. Health Policy and Planning 2009; 24: $36-45$

http://dx.doi.org/10.1093/heapol/czn042

[25] Tann C, Kizza M, Morison L, Mabey D, Muwanga M, Grosskurth $\mathrm{M}$, et al. Use of antenatal services and delivery care in Entebbe Uganda: a community survey. BMC Pregnancy and Childbirth 2007; 7(23).

[26] Bloom S, Lippeveld T, Wypiz D. Does antenatal care make a difference to safe delivery? A study in urban Uttar Pradesh, India. Health Policy Plan 1999; 14: 38-48. http://dx.doi.org/10.1093/heapol/14.1.38

[27] Mcdonagh M. Is antenatal care effective in reducing maternal morbidity and mortality? Health Policy Plan 1999; 11: 1-15. http://dx.doi.org/10.1093/heapol/11.1.1

[28] Magadi MA, Zulu EM, Brockerhoff $M$. The inequality of maternal health care in urban Sub-Saharan Africa in the 1990s. Popul Stud 2003; 57(3): 347-66. http://dx.doi.org/10.1080/0032472032000137853

[29] Stephenson R, Baschieri A, Clements S, Hennink M, Madise $\mathrm{N}$. Contextual influences in the use of health facilities for childbirth in Africa. Am J Public Health 2006; 96(1). http://dx.doi.org/10.2105/AJPH.2004.057422 